\title{
Civilisatie en emancipatie, maar van wie precies?
}

\author{
Twee eeuwen gevangen dertig jaar later
}

\author{
René van Swaaningen*
}

Na ruim dertig jaar mogen we Herman Frankes boek Twee eeuwen gevangen uit 1990 gerust een klassieker in de Nederlandse penologie noemen. Het is daarom bijzonder verheugend dat Jolande uit Beijerse en Miranda Boone het initiatief hebben genomen dit boek, in een veel mooiere uitgave dan het origineel, opnieuw uit te geven. Franke gebruikte in zijn boek de civilisatietheorie van Norbert Elias ([1939] 1982) om de ontwikkeling van het gevangeniswezen in de afgelopen tweehonderd jaar mee te verklaren. De vragen die ik in deze bijdrage aan het aan deze heruitgave gewijde themanummer van Justitiële verkenningen wil beantwoorden, zijn (1) hoe Elias' civilisatietheorie zich verhoudt tot andere verklaringsmodellen in de penologie, en (2) in hoeverre een eliasiaanse analyse van bestraffingspraktijken vandaag de dag overeind blijft.

\section{Vier paradigma's in de penologie}

Wat de theoretische verklaringsmodellen betreft is de penologie betrekkelijk overzichtelijk. In zijn eveneens in 1990 verschenen boek Punishment and modern society stelt David Garland dat alle verklaringen voor penologische ontwikkelingen uiteindelijk zijn terug te voeren op vier paradigma's, die zijn geënt op het werk van Émile Durkheim, Max Weber, Norbert Elias en Michel Foucault. Vervolgens integreert Garland deze vier paradigma's in een eigen theorie over 'penality', een term waaronder hij alle 'bestraffingsrituelen' schaart, los van de uitvoerende instituties. Mede omdat een dergelijke visie meer

\footnotetext{
* Prof. dr. R. van Swaaningen is als hoogleraar Criminologie verbonden aan de Erasmus Universiteit Rotterdam.
} 
aanknopingspunten biedt om recente ontwikkelingen in ons sanctiestelsel te analyseren, volg ik Garland hierin. Overigens is Garland niet uit op het aanscherpen van de tegenstellingen tussen de verschillende paradigma's, maar kijkt hij juist waar ze complementair zijn. Ook daarin volg ik hem. In deze paragraaf wil ik eerst de drie andere penologische paradigma's kort bespreken, om vervolgens wat dieper in te gaan op de civilisatietheorie. Vanwege de beperkte ruimte geef ik daarbij niet alle bronnen specifiek aan; in plaats daarvan verwijs ik naar het boek van Garland (1990).

Chronologisch gezien komen we in dit verband eerst op het werk van Émile Durkheim. Durkheims stelling was dat de manier waarop wij straffen een weerspiegeling is van de ontwikkeling van de maatschappij. Een tweede verklaringsmodel is geënt op Max Webers these over bureaucratisering en rationalisering, in casu van de manier waarop straffen ten uitvoer worden gelegd. Ten derde is er een paradigma waarin wordt uitgegaan van Norbert Elias' idee dat er in de moderne tijd een 'civilisatieproces' is opgetreden, doordat toenemende wederzijdse afhankelijkheden tussen mensen hogere eisen aan onze zelfbeheersing stellen. Hierdoor wordt een beweging zichtbaar waarin dwang van buitenaf (Fremdzwang) plaatsmaakt voor zelfbeheersing (Selbstzwang). En ten vierde komen we op verklaringen waarin wordt uitgegaan van een doelverschuiving van de straf. In een kapitalistische, industriële samenleving moet een gedisciplineerd proletariaat worden gecreëerd, dat zonder morren de monotone fabrieksarbeid verricht. In Michel Foucaults versie van dit van oorsprong marxistische paradigma gebeurt dat door de 'maatschappelijke dressuur' van de arbeidsdiscipline in verhevigde mate op te leggen aan diegenen die zich eraan willen onttrekken.

Émile Durkheim heeft feitelijk maar weinig over straffen geschreven, en al helemaal niet over het gevangeniswezen. Durkheims idee dat de betekenis van het straffen primair gelegen is in de maatschappelijke functie ervan, vloeit grotendeels voort uit zijn in 1893 verschenen boek La division du travail social. Doordat de rurale samenleving zich heeft ontwikkeld tot een industriële samenleving, heeft de traditionele mechanische solidariteit (waarin relatief vaststaande normen in een op persoonlijke relaties gebouwd verband worden doorgegeven en afgedwongen) plaatsgemaakt voor een veel complexere organische solidariteit: door de toegenomen arbeidsverdeling zijn intensievere onderlinge afhankelijkheden ontstaan, waardoor een directe, persoon- 
lijke sociale controle plaatsmaakte voor nieuwe, onpersoonlijkere en collectievere vormen van sociale controle.

Volgens Durkheim zouden we bij het analyseren van de samenleving moeten kijken naar de functie die een bepaalde praktijk heeft, en niet naar normatieve aannames of bedoelingen. In Durkheims functionalistische kijk op de strafrechtspleging is er echter wel sprake van een utiliteit van de straf op een hoger niveau: de straf hoeft niet per se functioneel te zijn voor de dader, maar voor de samenleving als geheel. David Garland (1990, p. 33) noemt dat de 'paradox van de hogere utiliteit'. In de nieuwe maatschappelijke constellatie van na de industriële revolutie functioneren bestraffingspraktijken als een soort collectief geweten (een conscience collective), waarin wat wij als samenleving goed- en afkeuren ten eerste wordt uitgedrukt in de bestraffing, en er vervolgens door wordt herbevestigd. Dit mechanisme heeft Durkheim in 1900 uitgewerkt in zijn essay Deux lois de l'evolution pénale.

De eerste penologische wet is volgens Durkheim dat bestraffingspraktijken minder hardvochtig zullen worden naarmate de maatschappelijke omstandigheden minder hard worden. Hierbij geldt wel dat het verblijf in de gevangenis altijd minder verkiesbaar moet blijven dan het leven in de vrije samenleving. Dit beginsel is vooral bekend geworden onder de Engelse term lesser eligibility - ofwel de geringere verkiesbaarheid. Hoewel de condities in de gevangenis dus altijd 'slechter' moeten zijn dan in de samenleving (anders is het geen straf), moeten zij ook weer niet zoveel slechter zijn dat een terugkeer in de samenleving door de ontmenselijking van de gedetineerde feitelijk niet meer mogelijk is. In die zin is de kwaliteit van de gevangenis een reflectie van de kwaliteit van de samenleving. De tweede penologische wet vloeit nog directer voort uit Durkheims theorie over arbeidsdeling. Omdat 'vrije tijd' een concept is dat pas in de industriële samenleving is ontstaan en de rol van lichamelijke arbeid toen geringer werd, nam de symboolwaarde van lijfstraffen af en werd vrijheidsbeneming de centrale straf.

Franke besteedt nauwelijks aandacht aan het werk van Durkheim. Volgens hem valt het buiten de scope van zijn boek, omdat het hem niet om de betekenis van de straf gaat, maar om het verklaren van veranderingen in de wijzen van bestraffing (Franke 1990, p. 9). Helemaal overtuigend vind ik deze redenering niet, ten eerste omdat beide mijns inziens niet los van elkaar zijn te zien, en ten tweede omdat het ook bij 
Durkheim gaat om het verklaren van een evolutie in de wijzen van bestraffing - zoals de titel van zijn enige echt penologische werk ook suggereert.

Wie Durkheims werk duidelijk wél heeft willen toepassen op de hedendaagse betekenis van 'misdaad en straf' is Hans Boutellier. Zijn boek Solidariteit en slachtofferschap uit 1993 gaat vooral over de morele betekenis van criminaliteit, en dus niet per se over bestraffing, maar het heeft wel duidelijke penologische implicaties, die denk ik het best zijn geanalyseerd door Tom Daems (2008). Hij ziet in Boutelliers analyse van de toegenomen aandacht voor het slachtofferperspectief een morele perspectiefwisseling in de penologie: de te handhaven norm is geënt op de victimologische vraag of er leed is ervaren. Normbevestiging is in de hedendaagse diverse, seculiere en technische samenleving problematischer geworden en daarom gaat het in het recht tegenwoordig veeleer om de vraag of de juiste procedure is gevolgd. Verderop in dit artikel zal ik Boutelliers werk nog nader confronteren met dat van Franke, maar eerst moeten we hier vaststellen dat in de laatmoderne tijd de 'irrationele' kant van het straffen misschien wel wat te weinig aandacht heeft gekregen, omdat we zo sterk gefocust waren op de rationalisering van bestraffingspraktijken. In die zin is de door Boutellier geëntameerde 'Durkheim-revival' een reactie op een dominant weberiaans perspectief in de penologie.

Van de 'grote vier' is Max Webers paradigma echter het minst geëxpliciteerd in de penologie; ik vermoed omdat rationalisering en bureaucratisering zó dominant zijn geweest in de ontwikkeling van het gevangeniswezen, dat het niet eens opviel als een specifiek paradigma. Herman Franke noemt Max Weber in zijn boek slechts één keer, maar tegelijkertijd is Webers these zichtbaar op bijna iedere pagina. Twee eeuwen gevangen is immers nadrukkelijk ook een geschiedenis van de professionalisering en bureaucratisering van de strafrechtspleging, waarin de wetenschap langzaam maar zeker de plaats inneemt van het geloof, technische kennis die van traditie en sentiment, en bedrijfsmatige routines die van morele oordelen. Een van de duidelijkste doorwerkingen van het weberiaanse paradigma in de hedendaagse bestraffingspraktijk is misschien wel het op basis van risicotaxaties categoriseren van verdachten en justitiabelen (Van Swaaningen 1996). $\mathrm{Nu}$ Webers angst dat de bureaucratische logica verwordt tot een 'ijzeren kooi', waarin de mens als het ware verdwijnt, lijkt te zijn bewaarheid (denk aan de manier waarop mensen zijn vermorzeld in 
de toeslagenaffaire in de kinderopvang of door het wereldvreemde regelfetisjisme van de IND, of aan het feit dat rationaliteit en transparantie in het huidige politieke klimaat lijken te zijn verdwenen, zie het coronabeleid en de 'Rutte-doctrine'), is het misschien tijd om ook Webers werk weer eens serieus af te stoffen.

Zoals Uit Beijerse en Boone (2020, p. viii) in hun inleiding tot de heruitgave van Twee eeuwen gevangen signaleren, zet Franke zich af tegen de toen breed gedeelde disciplineringsthese van Michel Foucault (1975) en de daaraan voorafgaande marxistische arbeidsmarkttheorie van Georg Rusche en Otto Kirchheimer, die net als Elias' civilisatietheorie óók het licht zag in 1939.

In Surveiller et punir, dat ondanks de grote invloed die het onmiddellijk na de verschijning van de Engelse editie in 1977 heeft gehad op de penologie opmerkelijk genoeg pas veertien jaar later in het Nederlands is gepubliceerd, onderscheidt Michel Foucault drie historische fasen in de ontwikkeling van bestraffingspraktijken. In de eerste periode, die van 1600 tot de Franse Revolutie loopt, staat de bestraffing van het lichaam centraal. Deze periode vat Foucault onder de term 'Tortuur' (Supplice). In de relatief korte tweede periode, die van 1789 tot de industriële revolutie loopt, staan de humanitaire hervormers centraal (Punition), en gaat het om de bestraffing van de geest en de ziel. Dit is ook de tijd waarin de door Franke gewraakte praktijk van de eenzame opsluiting (met de bijbel) in opkomst kwam. Na de industriële revolutie volgt een periode waarin het vooral gaat om de 'productie' van volgzame burgers. Deze periode wordt door Foucault gevat onder de term Discipline. In deze laatste periode is er volgens Foucault sprake van een 'grote opsluitingsgolf', waarin de straffen weliswaar minder bruut zijn geworden, maar - mede omdat het overheidsapparaat dan ook effectiever wordt - wel veel vaker worden toegepast. Dit gaat tevens gepaard met een rationalisering van bestraffingspraktijken. Door een strikte verdeling van ruimte en tijd fungeert de gevangenis als middel tot disciplinering en 'produceert' zij volgzame mensen. In de huidige tijd is de samenleving zelf volgens Foucault steeds meer gaan lijken op een gevangenis. Het alomtegenwoordige toezicht in de hedendaagse 'carcerale' samenleving vat Foucault onder de term Prison. 
Elias' civilisatietheorie als reactie op Foucaults disciplineringsthese

Hoe anders kijkt Herman Franke aan tegen de geschiedenis van het gevangeniswezen. Wat Foucault als een 'bestraffing van de ziel' ziet, noemt Franke een 'penologisch beschavingsoffensief'. Vanaf 1789 worden er minder mensen opgesloten, is er minder externe dwang en meer zelfdwang. In dezelfde lijn als Max Weber meent Norbert Elias dat er dan ook sprake is van een afnemende moralisering van misdaad, die gepaard gaat met een toenemende rationalisering van de straf. En dat gaat volgens de eliasiaan Franke vervolgens gepaard met steeds meer 'vrijheden' voor gedetineerden. Een van de meest aansprekende voorbeelden in dit verband is de vergelijking die Franke (1990, p. 782) maakt tussen het sterk moraliserende, in 1828 door Maatschappij tot Nut van 't Algemeen uitgegeven Zedenkundig handboek voor gevangenen en het sterk op de rechten van gedetineerden gerichte Bajesboek, in 1982 uitgegeven door de vereniging voor strafrechtshervorming, de Coornhert Liga, en de Bond van Wetsovertreders. Franke ziet hierin een emancipatie van gevangenen. Omdat Frankes uitgangspunt de eenzame opsluiting is, kun je al snel constateren dat gevangenen gaandeweg meer 'vrijheden' krijgen. Maar dat dat een emancipatie zou impliceren, daar is ook door de meest positief over Frankes werk oordelende recensenten de nodige kritiek op geleverd. Uit Beijerse en Boone (2020, p. viii) zeggen hierover:

'Zowel Van Ruller als Bovenkerk vragen zich overigens af of dit de juiste term is in dit verband. Van Ruller vindt dat het bij emancipatie uiteindelijk om gelijkstelling gaat en dat de afstand tussen de vrije en de onvrije Nederlander, ondanks alle verbeteringen, nauwelijks kleiner is geworden. Bovenkerk zegt dat emancipatie een kwestie is die van onderop wordt bevochten en niet (zoals in de analyse van Elias en Franke) van bovenaf wordt toegestaan.'

David Garlands theorie over bestraffing (penality) als een vorm van cultureel handelen (cultural agency) is gebaseerd op het idee dat bestraffing zowel een morele als een culturele boodschap uitdraagt en daarmee betekenis geeft aan normen. Mijns inziens is dat primair een durkheimiaans uitgangspunt, maar het aan Elias ontleende idee dat veranderende sentimenten en affecten van de burgerij in belangrijke 
mate hebben bijgedragen aan de 'civilisatie' van strafpraktijken speelt hierbij ook een belangrijke rol. Garland ontleent dit eliasiaanse element overigens vooral aan het werk van Pieter Spierenburg, die zich in zijn boeken over de afschaffing van publieke executies, The spectacle of suffering uit 1984, en over de opkomst van de gevangenis in de vroegmoderne tijd, The prison experience uit 1991, ook op Elias' civilisatietheorie baseerde. De (verkorte) Engelse vertaling van Herman Frankes boek over de definitieve vestiging van de gevangenis als belangrijkste straf aan het einde van de achttiende eeuw, dat de pakkender titel The emancipation of prisoners heeft meegekregen, is pas in 1995 verschenen.

In een publicatie over de sociale functie van openbare strafvoltrekkingen formuleerde Spierenburg twee kritieken aan het adres van Foucault. Aan de ene kant zou deze geen aandacht hebben voor het procesmatige: de gevangenis heeft nauwelijks een voorgeschiedenis bij Foucault en openbare straffen verdwijnen wel heel abrupt van het toneel. In een interview met Tom Daems en mijzelf zegt Spierenburg dat Foucault ten onrechte suggereert dat het verzet tegen het schavot pas tegen het einde van het ancien régime ontstond:

'Ik had echter empirische gegevens dat iedereen gewoon geïnteresseerd stond toe te kijken, behalve wanneer opstandelingen of stakers - mensen met wie de toeschouwers zich konden identificeren - werden gestraft. Dat zie je al in 1650. Dat was mijn belangrijkste punt van kritiek. (...) Onder historici heeft hij (Foucault) wel zijn tegenstanders, maar dat zijn dan toch vaak van die empiristen, die napluizen of alles klopt, maar die niet van theorie houden. Daar ging het mij niet om: ik houd we/van theorie, maar dan wel van goede theorieën. Dus ik dacht: "Nou, misschien is het publicitair wel goed als ik het boek expliciet als alternatieve benadering voorstel, tegen de benadering van Foucault." En dat heb ik zo ook gedaan. En tot mijn gedeeltelijke verbazing is het enorm opgepikt.' (Daems \& Van Swaaningen 2019, p. 24)

Mettertijd is Spierenburg milder over Foucault gaan denken, maar hij handhaaft wel twee punten van kritiek: er is geen sprake geweest van een snelle omslag in tachtig jaar tijd, maar van een langetermijnontwikkeling, en hij blijft kritisch ten aanzien van de wijze waarop Foucault het begrip 'macht' hanteert. 
Dat zal Herman Franke met hem eens zijn geweest, al is die wel veel negatiever over Foucault gebleven. Zo schrijft Franke (1990, p. 761): 'Het is zeer de vraag of Foucault geen onbedoelde gevolgen van justitiele reacties verwart met de beoogde uitkomsten van machtspolitiek en strategieën. Bovendien komt hij met deze analyses wel erg dicht in de buurt van komplottheorieën, ook al slaagt hij erin die met het rëficerend gebruik van abstracties als macht en kennis te vermijden.' En een paar bladzijden verder lezen we: '(...) hij reduceert individuen en groepen tevens tot instrumenten van een eigenzinnige, overal aanwezige en alles doordringende kracht: de macht. Mensen hebben zich maar naar de wensen van die macht te schikken. Zij doen dat zelfs zonder het te beseffen' (Franke 1990, p. 763).

Tussen dé twee eliasianen binnen de historische criminologie en penologie is vreemd genoeg vrij weinig contact geweest. In zijn recensie van Frankes Twee eeuwen gevangen was Spierenburg bijzonder positief, al meende hij wel dat Franke zich te veel liet meeslepen door zijn persoonlijke gevoelens c.q. zijn afkeer van de praktijk van de eenzame opsluiting. In Twee eeuwen gevangen vinden we wel wat plaagstootjes aan het adres van Spierenburg, die sommige van zijn aannames niet adequaat zou hebben beargumenteerd, maar daar blijft het wel bij (Franke 1990, p. 772). Herman Franke heb ik naar de redenen voor het geringe contact helaas niet meer kunnen vragen, maar in het eerdergenoemde interview zegt Pieter Spierenburg:

'In het begin hebben we wel wat wrijvingen gehad. Eigenlijk vond hij mijn benadering niet Eliasiaans genoeg; hij noemde het zelfs structureel-functionalistisch, wat het grootste scheldwoord was binnen de sociale wetenschappen destijds. (...) Ik had wel eens de indruk dat Herman Franke vond dat hij eigenlijk de grote man moest zijn bij het toepassen van Elias' historisch perspectief op de ontwikkeling van straffen en dat dat ook de achtergrond was van zijn theoretische aanvallen op mij.' (Daems \& Van Swaaningen 2019, p. 26)

\section{Een einde aan het vooruitgangsoptimisme}

Omdat zowel het idee van beschaving en emancipatie als dat van een veranderende moraal in beider werk zo'n prominente rol speelt, is het aardig om de visies van de neo-durkheimiaan Hans Boutellier kort te 
confronteren met die van de eliasiaan Herman Franke. Voor Franke impliceert beschaving vooral dat we fatsoenlijk omgaan met de 'verworpenen der aarde' en dus ook met mensen die iets verkeerds hebben gedaan. Voor Boutellier (1993) impliceert beschaving echter vooral dat de overheid de burger adequaat beschermt tegen onveiligheid. En terwijl beiden 'emancipatie' als een exponent van een veranderende moraal zien, is degene die zich emancipeert in beider werk een ander: bij Franke gaat het om de emancipatie van de gevangene, bij Boutellier om die van het slachtoffer. Waar Frankes boek een modern vooruitgangsoptimisme uitademt, leest Boutelliers boek eerder als een laatmoderne kritiek op een doorgeschoten lankmoedigheid.

Frankes vooruitgangsoptimisme is vandaag de dag mijns inziens niet goed vol te houden. Met de privatiseringsgolf van de jaren negentig zijn de winsten van het bedrijfsleven weliswaar fors toegenomen, maar in de publieke sector moest alles steeds meer voor een koopje - behalve als het om het inhuren van externe consultants ging. We kunnen denk ik moeilijk volhouden dat dat een positief effect heeft gehad op onze gezondheidszorg, het onderwijs of, inderdaad, op politie en justitie.

In deze neoliberale tijdgeest lijken we ook te hebben geaccepteerd dat de gevangenis haar betekenis niet ontleent aan enig nuttig effect op de criminaliteit, maar aan de boodschap die zij uitzendt. Het straffen is daarmee, om met Garland te spreken, een uitdrukking van autoriteit geworden. Naast de vaak genoemde teleurstelling over utilitaire doelen als resocialisatie, kan de heropleving van het vergeldingsdenken ook híermee worden verklaard. Vanaf de jaren negentig wordt de gevangenisstraf primair beschouwd als een middel om de samenleving te beschermen. Criminaliteit wordt steeds minder gezien als een gevolg van deprivatie en steeds meer als een symbool - zo niet een oorzaak - van sociaal verval, dat vooral om díe reden moet worden bestreden (Downes \& Van Swaaningen 2007).

We zijn in Nederland vanaf 2005, na dertig jaar toename, echter ook weer minder mensen gaan opsluiten en meer taakstraffen en elektronisch toezicht gaan opleggen. Uit deze ontwikkeling zouden we kunnen concluderen dat het eliasiaanse perspectief op straf nog steeds juist is. In een eerdere studie heb ik echter de vraag gesteld of die dalende detentiecijfers inderdaad impliceren dat we in Nederland ook minder punitief zijn geworden (Van Swaaningen 2013). Mijn antwoord 
is dat we deze daling vooral moeten zien in het licht van een voortschrijdend proces van bifurcation (de groeiende tweedeling in de wijze waarop straffen ten uitvoer worden gelegd: tussen 'gemotiveerden' en 'niet-gemotiveerden', tussen detentie en taakstraf, tussen straf en preventieve interventies), van een punitive city vol met in de samenleving ten uitvoer gelegde repressieve maatregelen, en van een toenemende 'prepressie', waarbij ook preventief bedoelde programma's steeds meer punitieve trekjes krijgen.

\section{Recente ontwikkelingen in de beheersing van criminaliteit}

Het lijkt misschien wat merkwaardig om onder het kopje 'Recente ontwikkelingen' met twee publicaties uit de vorige eeuw te komen, maar ik wil mij, net als in het voorafgaande, beperken tot de auteurs die een aantal voor de huidige tijd kenmerkende penologische ontwikkelingen het eerst signaleerden. Voor een concrete uitwerking van het hele palet aan laatmoderne 'veiligheidsassemblages' dat de afgelopen drie decennia is ontstaan, verwijs ik graag naar het boek Orde in veiligheid van Marc Schuilenburg (2012).

Op het ontstaan van een 'punitive city' heeft Stanley Cohen al in 1979 gewezen. Hiermee bouwt hij voort op Foucaults notie van de 'carcerale samenleving', waarin iedereen, overal, permanent in de gaten wordt gehouden. De doorwerking van allerlei beheersingsmechanismen in de samenleving brengt volgens Cohen een 'netwidening'-effect met zich mee. Er komen steeds meer sanctievormen bij, waardoor ook een telkens grotere groep mensen onder overheidscontrole komt.

Daarnaast is er sprake van 'mesh-thinning': doordat het net van sociale controle steeds kleinere mazen krijgt, worden er meer kleine 'visjes' gevangen. Nadat de opkomst van het moderne gevangeniswezen tot een 'grote opsluitingsgolf' leidde, wordt de sociale controle in de laatmoderne 'punitive city' nog verder geoptimaliseerd.

Een tweede tendens waar ik op wil wijzen, is wat Clifford Shearing en Philip Stenning (1987) de 'Disney-orde van sociale controle' noemen. Zij signaleren dat de sociale controle in attractieparken zeer efficiënt en effectief is, en dat de logica daarachter ook in toenemende mate zichtbaar is in de samenleving. Harde dwang maakt plaats voor vriendelijke overreding (nudging door Mickey Mouse en Goofy) en voor fysieke belemmeringen om de regels te overtreden - hetgeen in de 
criminologische literatuur 'designing out crime' wordt genoemd. Hoewel ook volgens Shearing en Stenning externe dwang altijd dicht onder de oppervlakte zichtbaar blijft, kan deze ontwikkeling met Elias' civilisatietheorie aardig worden verklaard.

Ook in het coronabeleid van het kabinet-Rutte III is aanvankelijk primair een beroep gedaan op de eigen verantwoordelijkheid van burgers om zich aan de maatregelen te houden en ging nudging, het vriendelijke zetje in de goede richting, boven dwang. Dit liberale beleid past perfect binnen een eliasiaans denkkader. Al snel bleek echter dat dit toch niet voldoende was en dat disciplinering door middel van externe dwang ook nodig was. Als demonstranten tegen de coronamaatregelen zich na een aantal keer vriendelijk vragen niet 'vrijwillig' verwijderen, volgen de lange lat en het waterkanon. Maar eigenlijk hebben we hier in Nederland een hekel aan: 'we' zijn erg goed in het uitvaardigen van heel veel, en vooral ook heel erg complexe regels, maar als het op handhaving aankomt, wijst 'men' het liefst naar elkaar. We laten bijzondere opsporingsambtenaren (boa's) rondlopen met jasjes waar met grote letters 'handhaving' op staat, maar wát er precies moet worden gehandhaafd, blijft onduidelijk. Desnoods handhaaf je jezelf - je maintiendrai!-, maar je handhaaft altijd iets; echter expliciet benoemen dat boa's de orde moeten handhaven, is voor Nederland klaarblijkelijk toch een stap te ver. Al met al kan ik met Foucaults disciplineringsthese, al dan niet door middel van dynamische publiek-private assemblages, uiteindelijk beter uit de voeten dan met Elias' civilisatietheorie.

\section{Conclusie}

Stanley Cohen heeft er altijd op gehamerd dat het ondanks onze 'intellectuele scepsis' zinvoller is om onze idealen en waarden te blijven benadrukken dan om een teleurgestelde cynicus te worden. In een essay over de erfenis van Cohen heb ik dat één van zijn belangrijkste bijdragen aan de (kritische) criminologie genoemd (Van Swaaningen 2017). En die impliciete boodschap waardeer ik ook in Herman Frankes boek Twee eeuwen gevangen. Maar zonder te willen suggereren dat 'de elite' het nu per se slecht met het 'gewone volk' voor zou hebben, ga ik van het idee dat zij een 'penitentiair beschavingsoffensief' zou nastreven toch ook wel enigszins steigeren (Franke 1990, p. 767). Mis- 
schien dat dat ooit zo is geweest, maar het 'verheffingsideaal' is inmiddels wel een echo uit een heel erg ver verleden. De huidige (demissionair) staatssecretaris voor het gevangeniswezen Sander Dekker is bepaald geen Modderman en ook geen Willem Pompe. In zijn boek richt Herman Franke de blik zelf nauwelijks vooruit, dus misschien is mijn vraag of een eliasiaanse lens nog wel bruikbaar is om hedendaagse bestraffingspraktijken mee te analyseren niet helemaal fair, maar toch denk ik dat het relevant is deze vraag te beantwoorden. Naast dat 'penitentiaire beschavingsoffensief' blijf ik ook aanhikken tegen het idee dat gedetineerden zouden zijn 'geëmancipeerd'. Frank Bovenkerk stelde terecht dat emancipatie iets is dat van onderop wordt bevochten en niet iets dat door elites wordt 'toegestaan'. En bovendien: wie heeft zich nu écht geëmancipeerd in de afgelopen drie decennia? Niet de gedetineerde dunkt mij. Het is de burger, en dan met name de boze burger, die zijn middelvinger opsteekt tegen de overheid, tegen 'de elite' en tegen mensen die in een kwetsbaarder sociale positie zitten dan zijzelf. Wat dat betreft denk ik dat Hans Boutellier, met zijn theorie over de emancipatie van het slachtoffer, de huidige tijdgeest beter vangt, ook al zouden we misschien willen dat Herman Franke nog steeds gelijk had. Maar helaas: een eventuele toegenomen gevoeligheid van de burger voor 'het lijden' richt zich bepaald niet op het lijden van kwetsbare groepen, maar veeleer op al het 'onrecht' dat hun zélf wordt aangedaan en alles wat 'de elite' van hen afpakt.

\section{Literatuur}

\section{Uit Beijerse \& Boone 2020}

J. uit Beijerse \& M. Boone, 'Herman Franke, Twee eeuwen gevangen. Misdaad en straf in Nederland, 1990', in: H. Franke, Twee eeuwen gevangen. Misdaad en straf in Nederland, Den Haag: Boom criminologie 2020, p. v-X.

\section{Boutellier 1993}

H. Boutellier, Solidariteit en slachtofferschap. De morele betekenis van criminaliteit in een postmoderne cultuur, Nijmegen: SUN 1993. 


\section{Cohen 1979}

S. Cohen, 'The punitive city.

Notes on the dispersal of social control', Crime, Law and Social Change (3) 1979, afl. 4, p. 339-363.

\section{Daems 2008}

T. Daems, Making sense of penal change: Punishment, vic-

timization \& society, Oxford: Clarendon 2008.

\section{Daems \& Van Swaaningen 2019}

T. Daems \& R. van Swaaningen,

"'Ik ben een beunhaas in de criminologie": in gesprek met Pieter Spierenburg', Tijdschrift over Cultuur \& Criminaliteit (9) 2019, afl. 11, p. 16-30.

\section{Downes \& Van Swaaningen 2007}

D. Downes \& R. van Swaaningen, 'The road to dystopia? Changes in the penal climate of the Netherlands', in: M. Tonry \& C. Bijleveld (red.), Crime and justice in the Netherlands, Chicago: The University of Chicago Press 2007, p. 31-72.

\section{Elias [1939] 1982}

N. Elias, Het civilisatieproces.

Sociogenetische en psychogenetische onderzoekingen, Utrecht:

Het Spectrum 1982.

\section{Foucault [1975] 1989}

M. Foucault, Discipline, toezicht en straf. De geboorte van de gevangenis, Groningen: Historische Uitgeverij Groningen 1989.

\section{Franke 1990}

H. Franke, Twee eeuwen gevangen. Misdaad en straf in Nederland, Utrecht: Het Spectrum 1990.

\section{Franke 1995}

H. Franke, The emancipation of prisoners. A socio-historical analysis of the Dutch prison experience, Edinburgh: Edinburgh University Press 1995.

\section{Garland 1990}

D. Garland, Punishment and modern society. A study in social theory, Chicago: The University of Chicago Press 1990.

\section{Schuilenburg 2012}

M. Schuilenburg, Orde in veiligheid. Een dynamisch perspectief, Den Haag: Boom Lemma uitgevers 2012.

\section{Shearing \& Stenning 1987}

C. Shearing \& P. Stenning, 'Say “cheese!” The Disney order that is not so Mickey Mouse', in: C. Shearing \& P. Stenning (red.), Private policing, Newbury Park: Sage 1987, p. 317-323.

\section{Spierenburg 1984}

P. Spierenburg, The spectacle of suffering, Cambridge: Cambridge University Press 1984.

\section{Spierenburg 1991}

P. Spierenburg, The prison experience: Disciplinary institutions and their inmates in early modern Europe, New Brunswick: Rutgers University Press 1991. 


\section{Van Swaaningen 1996}

R. van Swaaningen, 'Justitie als verzekeringsmaatschappij: "actuarial justice” in Nederland', Justitiële verkenningen (22) 1996, afl. 5, p. 80-97.

\section{Van Swaaningen 2013}

R. van Swaaningen, 'Reversing the punitive turn: The case of the Netherlands', in: T. Daems, S. Snacken \& D. Van Zyl Smit (red.), European penology?, Oxford: Hart 2013, p. 339-360.

\section{Van Swaaningen 2017}

R. van Swaaningen, 'Overdrijven en ontkennen: over de criminologische erfenis van Stanley Cohen', Tijdschrift over Cultuur \& Criminaliteit (7) 2017, afl. 1, p. 121-133. 